University for Business and Technology in Kosovo

UBT Knowledge Center

UBT International Conference

2012 UBT International Conference

Nov 2nd, 9:00 AM - Nov 3rd, 5:00 PM

\title{
The Risk-based Role of Internal Audit within Albania, Public Organizations
}

Holtjana Bello

European University of Tirana, hbello@yahoo.com

Vjollca Karapici

University of Tirana, v_karapici@yahoo.com

Follow this and additional works at: https://knowledgecenter.ubt-uni.net/conference

Part of the Business Commons

\section{Recommended Citation}

Bello, Holtjana and Karapici, Vjollca, "The Risk-based Role of Internal Audit within Albania, Public Organizations" (2012). UBT International Conference. 31.

https://knowledgecenter.ubt-uni.net/conference/2012/all-events/31

This Event is brought to you for free and open access by the Publication and Journals at UBT Knowledge Center. It has been accepted for inclusion in UBT International Conference by an authorized administrator of UBT Knowledge Center. For more information, please contact knowledge.center@ubt-uni.net. 


\title{
The Risk-based Role of Internal Audit within Albania, Public \\ Organizations
}

\author{
Holtjana Bello, PHD Candidate ${ }^{1}$, Prof.Dr.Vjollca Karapici ${ }^{1}$ \\ ${ }^{1}$ Finance Department, European University of Tirana, hbello@yahoo.com \\ 1 Accounting Department, University of Tirana, v karapici@yahoo.com
}

Abstract. The aspiration of Albania for European integration has added mandatory requirements for public sector to modernize the internal audit function in adherence with International Internal Auditing Standards.

According to such Standards supported by Picket (2005) and CIPFA (2003) the internal audit is an assurance function that provides independent opinion on the effectiveness of internal controls that support the achievement of the organizations objectives. Internal auditors can provide consultancy service, in particular to aid management to improve the organization control environment.

Meanwhile, Diamond (2002) explains that the internal audit role, remit, scope and activities are driven by the macroeconomic objectives and political stabilization. For those countries with governance problems the first objective is to ensure compliance with financial laws and regulations. Therefore, the most suitable approach for the internal audit is the compliance auditing to attain macroeconomic stabilization objectives.

Therefore, the main question around which this paper is based is whether the public sector in Albania is ready to adopt the modern model of internal audit moving beyond the traditional compliance and financial remit to comply with recognized International Internal Audit Standards.

This paper finds that although changes in Albanian normative framework since 2007, internal audit within government organizations are still adopting traditional approach of internal audit involving financial inspections rather than performance auditing activities aiming to provide opinion on risk management, control and governance.

This paper analyzes that the embryonic risk culture of Albanian public sector, the lack of skilled internal audit resources and a little understanding of both managers and internal auditors with regard to the contribution of internal audit in risk management and corporate governance system aimed at achieving the government organizations objectives are the main reasons why the risk based model and consultancy role of internal auditors is not yet applied.

Therefore, this paper recommends the internal auditors to perform additional consultancy tasks to enhance the internal control system and build the risk management methodologies and structures due to the management lack of knowledge. As soon as the organizations become risk mature the internal auditors can provide assurance appraisal service based on risks. The Practice Advisory Standard 1000 recommends principles which should be used as guidance for regulatory framework of internal audit function within Albania, public sector, guiding internal auditors in order for them to maintain their independence, objectivity and due professional care while conducting consulting service.

Keywords: Public Sector, Audit, Corporate Governance, Internal Controls, Risk Management 


\section{Introduction}

The purpose of this paper is to explore the role of internal audit in Albania, public organizations. The aspiration for European integration has triggered modernization of such function moving beyond the traditional compliance and financial remit in adherence with International Internal Audit (IIA) Standards. Moreover, the direct responsibility given to the Albanian government for the management of European Union funds in a cost-effective and transparent way adds mandatory requirements for the public sector to comply with IIA professional standards (SIGMA, 2009).

The potential weaknesses of internal auditing model adopted within Albania, public sector such as the lack of consulting role with regard to risk management as well as the lack of knowledge of senior managers for the shifting role of internal auditors beyond finance auditing, modest capabilities of internal auditors with regard to risk issues are identified as main reasons for Albanian public sector to still develop the traditional role of finance and compliance internal auditing.

Furthermore, this paper identifies gaps between normative framework and the internal audit practice with regard to annual aud it plan and internal audit activities. Cyclical audit plan is approached by public organizations versus the risk model suggested by the IA Manual and although changes in the law the internal auditors still carry out financial inspection work rather than int ernal audit activities as the IA Manual suggests.

The practices and models identified through this literature review are compared with audit approach adopted within Albania, public sector and after assessing the factors and circumstances that trigger any changes, considerations are made to enhance internal audit profession and co-develop the internal audit model based on the best global practice.

Therefore, the annual audit plan is suggested to be risk based approach with internal auditors playing a consultancy role to the management in terms of identification, assessment, prioritization of risks that impact the entire strateg $y$ and the reputation of public institutions.

\section{Literature review}

\subsection{The modern role of internal audit}

The starting point for internal audit role is the definition of internal audit.

"Internal auditing is an independent, objective assurance and consulting activity designed to add value and improve an organization operations. It helps an organization accomplish its objectives by bringing a systematic, disciplined approach to evaluate and improve effectiveness of risk management, control and governance processes". (IIA, Standard 1000)

Different organizations have developed their model of internal auditing based on such definition. There are organizations whe re auditors feel that they should police the organization, while there are others that struggle on good value for money and improved ways of using resources. Still other auditors depend on the audit charter and management expectations, while much other are reviewing risk management and controls (Picket, 2003).

The shifting role of internal audit beyond the traditional police internal auditor started after the failure of WorldCom. There were a number of deficiencies identified in the corporate governance practices and the internal audit work such as reporting line of internal auditors to the senior management, the narrow operational focus of internal audit, little meaningful communication among stakeholders, audit resources insufficiency although utilized by management for non audit work, the shallow view of Audit Committee, all trigger new changes in the internal audit role, remit and activities. These, changes demand for internal auditors to strike the right balance between differing needs and expectations of stakeholders and to add value without compromising independence and credibility (Abbey Consulting, 2009).

Therefore, there is no one right model of internal audit defined and the final role adopted depends on the best professional practice, expectations of the organizations and skills and capabilities of the audit staff. Additionally, the head of internal audit has a great impact on the role definition as the most responsible person in the delivery of audit services (Picket, 2003).

Another useful model for internal audit role is described again by Picket (2003), as the function which is more concerned about future controls than past events. 
"Such model is quoted by Prof. Vinten from unpublished course notes, who emphasize the need to direct audit resources at the future welfare as opposed to being preoccupied with past events in the form of recorded transactions and incidents that have already occurred". (Picket, 2003:242)

Furthermore, according to Picket (2003), CIPFA (2003), Chartered Institute of Public Finance and Accountancy, the United Kingdom professional accountancy body specialized in public services, has adopted internal audit IIA definition as the assurance function that primarily provide independent and objective opinion on the effectiveness of internal controls that su pport the achievement of the organization objectives. Internal au dit can also provide independent and objective consultancy service, specifically to aid management to improve the organization control environment.

Diamond (2002) views the internal audit role in the public sector from the entirely different perspective. The author explains that internal audit remit, scope and activities are driven by the macroeconomic objectives and political stabilization. For those countries with governance problems, the first and foremost objective is to ensure compliance with the financial laws and regulations. Therefore, the governments are likely to involve a more centralized approach to internal audit and to limit its role to compliance auditing to attain macroeconomic stabilization objectives. Conversely, for developed economies to obtain the management objectives of efficiency in the delivery of service, a more decentralized approach to internal auditing by widening its role to performance auditing, is adopted.

In the United Kingdom the government internal audit manual has developed the internal audit role based on IIA standards.

PWC (2009) describes a new focus of internal audit on the light of the emerging risks threatening the organizations. These hardto-predict and high-impact risks are characterized by potentially interdependent consequences which drive the need for internal audit focus to be aligned to the changing business priorities. Moreover, these risks demand the shift in focus from financial reporting controls toward the sources of risk that destroy shareholder value.

Recent studies indicate that strategic and business risks pose greater threats to shareholder value than operational, complia nce, or financial risks. (PWC, 2009:9)

Notwithstanding this, according to State of Profession survey for the UK and USA market, there are many internal audit functions that have directed resources to the traditional financial risk hence, being focused on the financial reporting audits and compliance controls (PWC, 2009).

However, the current trend for internal audit role is to move toward a consultancy-based approach (Picket, 2003).

\subsection{Annual audit plan}

This section emphasizes that a credible plan of the audit process help the internal auditors to contribute to better governan ce, risk management and more effective controls.

"The Chief Audit Executive should establish risk-based plans to determine the priorities of the internal audit activity, consistent with the organization's goals", (Practice Advisory, Standard 2010)

Picket (2003) discusses that audit planning is an area that should respond to the demands and new challenges posed for the internal audit profession. Planning is about defining expectations and focusing resources to achieve more effective results. Effectiveness stands on the fulfillment of several objectives such as establishing good relations with client; developing a better control environment in the organization; promoting processes that respond effectively to risks that impact the organization's objectives; promoting a culture that encourages compliance with procedures.

Audit strategic planning involves three alternative approaches which are given in turn:

The traditional planning-cyclical audit is a model that involves looking at everything on cyclical basis over three year periods. In the absence of a risk register, the internal auditors should define a list of risks the organization is facing prioritizing the systems known to internal audit to be poorly controlled and those of particular concern to senior managers. Additionally, factors such as materiality, impact on reputation, state of controls are used to assess the risk universe and prioritize the risky areas.

The second approach is a more advanced method which revolves around the corporate governance framework. Audit resources are directed to review governance framework such as board arrangements and accountability, the role and impact of audit committee, control framework in use, communication across the organization, risk assessment and risk management arrangements, all aiming to promote good corporate governance. 
The last method, internal audit risk-based planning reflects the combination of the supporting and consulting role in helping the organization to establish risk management and auditing of the high risky areas consistent with the organization's goals (Picket, 2003).

"The risk-based audit planning is an approach to audit work that focuses on strategic, regulatory, financial and business risk that confront the organization and which uses these risk to steer the audit process in a way that maximizes the impact of audit assurance and consulting work”. (Picket, 2006:3)

Picket (2006) has formulated the holistic approach to risk-based audit planning as a concept that is aimed at shifting the audit process into boardroom agenda and allowing the auditors to audit new horizons. This model is about corporate governance arrangements incorporated into the risk-based plan approach as a paramount to improve governance processes. Promoting appropriate ethics and values within the organization; assuring effective performance management and accountability; communicating risk and control information to the appropriate areas of the organization; coordinating activities among the bo ard, external and internal auditors and management, are the ideals the audit plan should start with to reach to the highest level of performance.

The next item to feed into the planning process is the expectations and requirements of the board, since it is the body that needs to ensure compliance with relevant law and regulation; safeguarding of assets; delivering of the objectives through setting the right strategy; the adequacy of internal controls system to guard the business against the risk of failing.

Furthermore, the needs and expectations of Audit Committee members are considered as valuable insights to be taken into considerations as they stick to achieve the corporate disclosures and compliance.

- "Corporate disclosures is the organization need to establish a system for providing disclosures regarding matters such as internal controls over financial reporting and corporate ethics

- Compliance is the organization need to be sure that the system above is fully understood and applied throughout the organization”. (Picket, 2006:233)

Additionally, the external auditors need to be appeared into this planning model because of their relationship with internal audit to ensure unnecessary duplication of audit work.

"Planned audit activities of internal and external auditors should be discussed to assure that audit coverage is coordinated and duplicate efforts are minimized”. (IIA, Standard: 2050)

Finally, the input from senior management into the audit planning process is considered vital to the establishment of good controls either in a consulting or assurance role since the management is primary responsible with the validating of control environment. This control environment include integrity and ethical value, management's philosophy and operating style, assignment of authority and responsibility, human resource policies and practices. The internal auditors assist the management to discharge this role. However the degree of involvement should be agreed with all concerned parties.

"The degree to which the internal audit activities constitute management testing of controls should be cle arly specified and agreed to by management, internal audit and audit committee”. (Picket, 2006:238)

Cain (2006) stick on the annual audit plan-risk based approach as a methodology that links internal audit to the organization's overall risk management framework. This model allows internal audit to provide assurance to the board that risk management processes are managing risks effectively. However, it describes the risk maturity stance of the organization as a preconditio $\mathrm{n}$ for the development of risk approach to internal audit planning. For the organization with an embryonic risk culture the promotion and facilitation of risk management processes among managers by internal auditors and reliance of alternative planning method s, are recommended.

PWC (2003) support this idea by presenting the challenges perceived nowadays by senior managers, to quantify risks, to resolve conflicts in corporate priorities, to identify and measure ERM benefits and to embed risk management into business processes. Therefore the facilitator role of internal audit in a frequently enterprise-wide risk assessment is viewed to be vital in understanding of the risk management processes.

"There is also recognition that internal auditors can facilitate a greater understanding of risk ma nagement processes and issues among their executive management groups and audit committees". (Picket 2003:18) 
Furthermore, Picket (2006) has developed a Risk Managements Levels theory. The author suggest there are three levels of risk management maturity and the audit approach is adopted according to the level at which the organization stands.

\section{$\underline{\text { Risk Status and Audit Approach }}$}

- Level 1 (Silo) - This is the early stage in the development of an ERM process, where various parts of the organization work in isolation to assess risk. There is no common ground view of risks and therefore consistency in assessing priorities and managing exposures is lacking.

At this level auditors may assume the role of a Risk Champion to aid organization to set up the concept of ERM.

- Level 2 (Cheese) - There is a risk based activity developing in the organization, but it is not yet related to an enterprise wide approach and the corporate standard that pull the different efforts along is lacking.

This is the level where the organization enhances a better understanding of risk as the ERM maturity develops. At this level internal auditors are encouraged to aid the managers to review their controls in proactive manner relaxing controls that are needless and make the business less competitive.

- Level 3 (Inclusive) - This stage mostly refer to as ERM, where the entire organization has a common understanding of risk concept, recommended methodology, available tools and clear view of risk appetites for all parts of the business. At this level, the auditors assume an assuring role (Risk Validation) on the adequacy of the existing ERM arrangements.

Finally, there are a number of options for planning the audit work. However, the organizations should adopt the approach that take into consideration its risk appetite, environment and organizational culture. Whatever approach is adopted, internal audit should ensure whether the plan fits with the way the organization responds to corporate governance; it is mainly driven by risk register; the board accepts it as the best way to apply audit resources; it is dynamic, flexible and responds to the changes of risk management and accountability (Picket, 2003).

\section{Internal audit in Albania}

\subsection{Methodology}

In order to undertake this research, qualitative research techniques are utilized to gather data for this project. The responses obtained from the semi-structured interviews are complemented with secondary data made available from government publications and other reliable sources with regard to the development of Internal Audit within Albania, public sector.

\subsubsection{Type of primary data}

The purpose of data collected by the interviews undertaken with General Director of Center Harmonization Unit (CHU), Heads of Internal Audits within public sector and HSC auditor is to explore in more detail the information gathered from secondary source of data. Given thematic nature of such information the responses from interviewees are also cross -checked with related information within the same theme to provide an additional, in depth analysis of the data gathered.

The focus of questions to Director CHU is to understand the priorities of government with respect to internal audit professio n.

HSC auditor is interviewed to expand a variety of perspectives to be obtained from the external auditor's point of view. How they cooperate with internal audit functions to avoid overlapping experiences and at what extent they assess the work of inte rnal audit units is also the emphas is of this research.

Heads of Internal Audits of local and central governmental organizations are interviewed with different focus and the emphasis of this dissertation is on the approaches employed in auditing the organizations, the nature and extent of establishing risk-based auditing, availability of resources in terms of capabilities and skills.

\subsubsection{Type and source of secondary data}

The secondary data used in this research are time series of data provided by SIGMA 2008/2009/2010/2011 in a project undertaken by EU to independently assess the progress of Albania in adopting and implementing the principles for a financial management of the public funds, the fulfillment of which is a precondition for Balkan countries to be EU member (SIGMA, 2008). 
This information is supplemented by data gathered from the document PIFC Policy Paper

published by the Government in June 2009, which describes the steps undertaken by Albania Government to update and improve internal control system, including internal auditing.

Subsequently, the information gathered is cross-checked with data obtained from Internal Audit Manual 2010 and Internal Audit Law 2010.

\subsection{Internal audit role}

The Internal Audit Law 2010 is the document that forms a basis for internal audit legal and institutional development in Alba nia.

Internal audit law reflects recognized IA standards defining the internal audit as an appraisal service within organization that provides an assurance opinion on the degree to which the internal controls support the achievement of objectives. Additionally, upon the request of the Accounting Officer (Minister, Director of Agency) of the public institution, the IA can provide a consultancy service to improve internal control environment, risk management and corporate governance. However, if the need for the consultancy provided from IA is raised the scope, remit and constraints of such activity will be regulated upon internal legal acts issued from the office of Minister of Finance.

From theoretical perspective, the internal audit function within Albanian public institution is risk based audit and "it covers compliance and substantive tests, system audit, performance audits, IT audits and any other kind of ex-post verification that is considered necessary to ensure compliance of management with financial rules and regulations of the organizations". (Council of Minister, 2009:12)

Notwithstanding this theoretical approach, the main question the public sector face is whether the public institutions are riskmature enough to enable internal auditors to provide risk- based assurance audit services.

The Literature Review chapter emphasizes that the audit role needs to be related to where the organization stands in terms of the development of risk management. Therefore the role of internal audit is to facilitate and coach the risk management process assisting the management in setting up the concept of risk at the early stage of its development unless the organization introduces risk management function leaded by capable staff in risk management field. As risk management develops the internal audit the consulting role shift toward more assuring task furnishing the management with adequacy of risk management arrangements.

While effectiveness of internal control is defined as the main contribution and the key role of internal audit within Albania, public sector, risk management and corporate governance are the new concepts introduced recently and therefore they are not provided for as activities falling under internal audit scrutinization.

According to the PIFC Policy Paper (2009), it is responsibility of public entity's management to develop effective methods for identification and assessment of risks and build internal control procedures to prevent such risks. IA Manual (2010) emphasizes " the consultancy role of internal audit in developing projects of implementing new internal controls systems" (pg:17) but, does not foresees the IA consultancy role in promoting and facilitating the development of effective system of risk management i.e. through addressing the basic risks due to the low level of risk maturity of government organizations.

Furthermore, according to SIGMA (2011), internal auditors are not perceived as adviser to the executives but, still as financial inspectors although the changes in the internal audit law that have separated internal audit from financial inception aiming to clarify the role of internal audit as not solely as a "control" function.

However, the question added is whether internal auditors in both consulting and assurance service have sufficient skills and expertise in dealing with risk issues?

Based on the interviews with head of internal audits, there is a little understanding in practice of the new role of internal auditing based on risks and therefore even the system-based auditing has not yet been heavily incorporated into the internal audit plan. Therefore, the audit services within Albania, public sector remain the traditional type of audits focused on financial issues by carrying out test programmes, spot checks and compliance auditing.

"Until now the audit engagements are mainly financial inspection. Other audit engagements

such as IT, HR, Communication, Legal are new concept ready to be introduced in the ongoing annual audit plan. Contribution of auditors in the area of environment, Health and Safety, Business Continuity plan, Business Contingency Plan, Emergency Plan is not yet developed", says Director Internal Audit of local government organization.

Furthermore, the question faces the public sector regarding the role of internal auditing as a "control" function" is how the internal audit can evaluate the efficiency and effectiveness of the internal controls without understanding the risks that ne ed to be addressed by these controls? 
SIGMA (2011) provides a valuable recommendation to the Ministry of Finance to deliver practical trainings to internal auditors as well as to high senior public officers including ministers, general secretaries, and head of agencies for the modern and value added role of internal auditor as consultants in risk management and governance arrangements.

\subsection{Annual Audit Plan}

From theoretical perspective the annual audit plan adopted within Albania, public sector is risk-based approach. What factors should be taken into consideration, how to weigh and rank the risks, what is the audit universe, how to prioritize the audit areas, all of which are described in the IA Manual.

Notwithstanding this, according to the responses obtained by the head of internal audits this methodology is not yet implemen ted in practice. The government organizations are still operating a cycle of routine audits by targeting each part of the organization from one to every three years. However, there is a basic risk assessment work performed by internal audit units to prioritize the highest scoring areas due to the limited resources required to cover all the audit areas of the organization within the cycle of three years time. Some of the risk criteria that are used for such purpose are as following:

- the areas that receive more funds

- $\quad$ size of the workforce

- number of complaints from customers

- number of reported thefts and fraud

It is the opinion of the researcher that the understanding of risk management concept among the managers, directors and internal auditors is still embryonic. The method used from internal auditors to assess the risk look to be an old-format with the internal auditors being financial inspectors resulting in a low profile of audit process, many missed areas to be reviewed and detaile $\mathrm{d}$ descriptive reports.

Moreover, this type of approach directs the audit resources at accounting system where the questionnaires and check list used by external auditors are adopted and used by internal auditors, "it is clear that the day to day operations are still very basic and still relate more to the previous role of financial inspection than to modern internal audit activities. It is very disappointing that after a period of nine years the role of internal audit is still misunderstood and confused with ex post controls". (SIGMA, 2009:9)

In Albanian internal audit practice the external auditors are not linked into internal audit planning process. Based on the interview with the HSC auditor, there is neither scheduled meeting during the audit planning nor any other form of communication between external auditors (HSC) and the internal audit team to assure the coordination of audit coverage and to minimize duplication of efforts.

Furthermore, based on the interviewees with heads of internal audits, there is a limited feedback and contribution from senior management into audit planning process and there is no discussion with them about their risk assessment and key controls built to manage those risks. Indeed, the management participation into audit plan within Albania, public s ector implies employment of resources in terms of time and people toward special investigation cases upon the management request.

Conclusively, this approach to planning does not involve expectations and views from important senior management and other stakeholders to be compiled in a discussion paper (Picket, 2006). Therefore, this type of annual audit plan adopted within Albania, public sector might not correspond to the views of senior management, who might have different priorities, resulting in an internal audit function not adding value to the organization and not assisting the management to achieve their objectives.

According to the Director CHU,"the strategic focus of the Government these years has been to make reforms of legal and institutional framework thus, changing the organization structures aiming to shift the culture of government organizations toward a new internal audit approach, building a new methodology to underpin performance auditing, educating the managers with the new role of internal audit, and certifying the auditors who in fact, are still financial inspectors. Therefore, the full implementation of the audit approach adopted within Albania, public sector including the annual audit plan risk-based approach which enables the auditors to target the high-risky areas and to promote risks within organization as well as enhance their daily work required in adherence with internal audit standards, will take several years".

\section{Conclusions and recommendations}

The result obtained from the interviews and secondary data identifies that Albania has adopted recently the IIA standards within public sector. Budget users in all levels, either central or local governments are financed by budget funds. Therefore they a re 
obliged to regulate the system of internal auditing aiming to ensure the well-functioning of an appropriate risk management and internal control system within the core business.

The audit approach strategy from theoretical perspective is that of risk-based model that covers area beyond traditional audit activities such as finance auditing. However, performance and information technology auditing and reporting wider strategic issues are relatively new concepts across the public sector as the experience of risk-based auditing is emerged recently as the chosen way forward. Therefore, the current position of internal auditing within public sector, in Albania drives the new role of internal audit in championing the management toward the risk business culture. It emerges the need of specialists with not only accounting background but with multi-disciplinary skills which apparently, are lacking across the public sector resulting in traditional and limited audit activities performed by existing audit resources.

\section{Recommendation 1}

The role of internal audit should encompass the consultancy task of internal audit function, in particular, to enhance the internal control system and to build the risk management methodologies and structures due to the management lack of knowledge. The Practice Advisory Standard 1000, recommends principles guiding the consulting engagements of internal audit which, can be used as a guidance also for the regulatory framework of internal audit function within Albania, public sector. Furthermore, the principles recommend that empowerment of internal audit activity with the consulting role needs to be reflected into internal audit charter of each public organization. Additionally, the standard requirements regarding the independence and objectivity to be maintained in consulting engagements, due professional care, objectives to meet and scope of work, documentation requirements, communication of results and monitoring of consulting engagements need to be tailored to each government organization's characteristics and thus, to be included into internal audit charter.

\section{Recommendation 2}

Based on the risk maturity model explained in Literature Review, the internal audits may act as risks champions due to the lack of management knowledge regarding risk management process, "internal auditors may provide trainings and information on internal control identification and assessment, risk assessment without impairment of objectivity. As the organization's cont rol experts, this would be a natural role”. (Picket, 2006: 4)

In order to apply the audit resources in line with management priorities, the internal audit may consider moving away from cyclical plan to adopt a risks-based approach by taking into board the expectations of stakeholders, input from management, considerations from HSC to avoid duplication of efforts. Additionally, this approach should promote the wider view of risks beyond the finance and compliance and regulatory matters to raise the awareness of managers for the shifting role of internal audit toward performance auditing and consulting commitments.

\section{References}

Abbey Consulting. (2009) Chief Internal Auditors'Symposium. London

Albanian Internal Audit Directorate. (2007) Internal Audit in Public Sectorin Albania(online)

http://www.minfin.gov.al/downloads/3Leksione-\%20Bazat\%20e\%20AB.pdf (Accessed on 12 July)

Albanian State Supreme Audit.(2009)Performance Audit Manual(online).Tirane,

http://www.klsh.org.al/doc/20090402161844PerformanceManual.pdf (Accessed on September 2012)

Baker,N. (2010). "Board Games”. Internal Auditing, March, p.18.

Cain, J. (2006) An Approach to Implementing Risk Based Internal Auditing. London: Institute of Internal Auditors UK and

Ireland

European Commission. (2009) Institution Building in the Framework of European Union Policies Common Twinning Manual

(online)

http://ec.europa.eu/enlargement/pdfffinancial assistance/institution building/final version of the manual 2009 clean en.pdf

(Accessed on September 2012)

HM Treasury. (2007). Audit Committee Handbook (on line). London: Available from http://www.hmtreasury.gov.uk/d/auditcommitteehandbook140307.pdf (Accessed on Septemeber 2012) 
Miekatrien, S. (2006). International Audit Trends in the Public Sector: a comparison of internal audit functions in the governments of six OECD countries finds similarities in legal requirements, organizational structure, and future challenges (on line).

http://www.allbusiness.com/sector-54/professional-services-accounting/1194095-1.html_ (Accessed 27 July 2012)

MIS. (2009) Chief Internal Auditors'Symposium. London

Picket,S.(2003) Internal Auditing Handbook. New Jersey: Wiley

Picket,S. (2006) Audit Planning a Risk Based Approach. New Jersey: Wiley

PWC. (2007) State of the internal audit profession study:

Pressures build for continual focus on risk (online)

http://www.pwc.com/en US/us/internalaudit/assets/state internal audit profession study 07.pdf (Accessed on September

2012)

PWC. (2009). Business upheaval: Internal audit

weighs its role amid the recession and evolving enterprise risks. Available from

http://moodle.bcu.ac.uk/bcbs/course/view.php?id=607 (Accessed on 30 August 2012)

Republic of Albania, Parliament. (2007) Audit Law (online).Tirane

http://www.google.com/search?client=firefox-a \&rls=org.mo zilla\%3Aen-

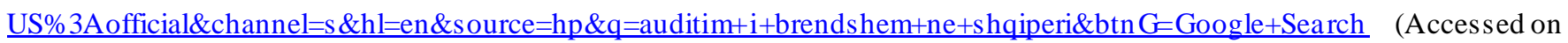
October 2012)

Republic of Albania, Ministry of Finance. (2009) Internal Audit Manual (hard copy). Tirane

Republic of Albania, Parliament. (2010) For some amendments in the Law 9720 of the date 23.04.2007 on "Internal Audit in Public Sector" (online). Tirane http://www.minfin.gov.al/downloads/draft\%20Internal\%20audit\%20Law.pdf (Accessed on October 2012)

Republic of Albania, Ministry of Integrity. (2010) Management of Public Finances (online)

http://www.mie.gov.al/?fq=brenda\&m=shfaqart\&aid=286 (Accessed on 12 July)

SIGMA. (2007,2008, 2009, 2011) Assessment Reports, Public Internal Financial Control (online)

http://www.oecd.org/document/51/0,3343,en $33638100 \quad 34612958 \quad 35852275 \quad 1 \quad 1 \quad 1 \quad 1,00 . h t m l$ (Accessed on October 2012) $\underline{\text { www.eciia.eu }}$

www.iaid.gov.mt/home

www.iia.org.uk/

www.theiia.org 